OPEN ACCESS

Edited by: Niels Janssen,

University of La Laguna, Spain

Reviewed by: Elin Runnqvist,

Laboratoire de Physique des Lasers

(CNRS), France

Shota Monma,

University of California, San Diego,

USA

*Correspondence:

Lesya Y. Ganushchak

Iganushchak@gmail.com

Specialty section:

This article was submitted to

Language Sciences,

a section of the journal

Frontiers in Psychology

Received: 26 May 2016 Accepted: 08 February 2017

Published: 28 February 2017

Citation:

Ganushchak LY, Konopka AE and

Chen Y (2017) Accessibility of Referent Information Influences

Sentence Planning: An Eye-Tracking

Study. Front. Psychol. 8:250. doi: 10.3389/fpsyg.2017.00250

\section{Accessibility of Referent Information Influences Sentence Planning: An Eye-Tracking Study}

\author{
Lesya Y. Ganushchak ${ }^{1,2,3 *}$, Agnieszka E. Konopka ${ }^{4}$ and Yiya Chen ${ }^{1,5}$
}

${ }^{1}$ Leiden University Centre for Linguistics, Leiden University, Leiden, Netherlands, ${ }^{2}$ Education and Child Studies, Faculty of Social and Behavioral Sciences, Leiden University, Leiden, Netherlands, ${ }^{3}$ Department of Psychology, Education and Child Studies, Erasmus University Rotterdam, Rotterdam, Netherlands, ${ }^{4}$ School of Psychology, University of Aberdeen, Aberdeen, UK, ${ }^{5}$ Leiden Institute for Brain and Cognition, Leiden University, Leiden, Netherlands

This study investigated the time-course of online sentence formulation (i.e., incrementality in sentence planning) as a function of the preceding discourse context. In two eye-tracking experiments, participants described pictures of transitive events (e.g., a frog catching a fly). The accessibility of the agent (Experiment 1) and patient (Experiment 2) was manipulated in the discourse preceding each picture. In the Literal condition, participants heard a story where the agent or patient was mentioned explicitly (fly, frog). In the Associative condition, the agent or patient was not mentioned but was primed by the story (via semantically or associatively related words such as insect, small, black, wings). In the No Mention condition, the stories did not explicitly mention or prime either character. The target response was expected to have the same structure and content in all conditions (SVO sentences: The frog catches the fly). The results showed that participants generally looked first at the agent, before speech onset, regardless of condition, and then at the patient around and after speech onset. Analyses of eye movements in time window associated with linguistic planning showed that formulation was sensitive mainly to whether the agent was literally mentioned in the context or not and to lesser extent to conceptual accessibility (Experiment 1). Furthermore, accessibility of the patient (be it literal mention of its name or only availability of the concept) showed no effect on the time-course of utterance planning (Experiment 2). Together, these results suggest that linguistic planning before speech onset was influenced only by the accessibility of the first character name in the sentence, providing further evidence for highly incremental planning in sentence production.

Keywords: sentence planning, eye-tracking, givenness, incrementality, discourse context, accessibility

\section{INTRODUCTION}

To produce a sentence, speakers need to prepare a preverbal message and then encode it linguistically. Preparation and encoding of messages and sentences are assumed to proceed incrementally (e.g., Kempen and Hoenkamp, 1987; Konopka and Brown-Schmidt, 2014). Evidence for incremental planning, however, has come mainly from work on production of individual sentences out of context. Despite the communicative function of speech, little is known about planning of utterances as a function of the discourse context in which they are produced. The aim 
of this project is to investigate how sentence planning is affected by discourse context. In particular, we will examine how accessibility of information about characters in simple events (manipulated as specific information provided about these characters in the preceding discourse context) affects the timecourse of planning.

Accessibility of information about any element of the preverbal message and corresponding utterance is assumed to be a continuous measure of the degree to which a referent is "active" in that particular context. Any referential expression produced in a sentence (e.g., the frog or it) may be placed on a "continuum" of accessibility, depending on the context. At one end of the continuum, an expression can be completely new, or inactive in the speaker's mind, and may need to be encoded from scratch, both conceptually and linguistically, during the planning of an utterance. At the other end of the continuum, a referring expression can be regarded as being completely given and active in the speaker's mind at the time of planning. This variability in the accessibility of a given concept can be driven by multiple factors, such as attention allocation and discourse context. For example, referents can vary in accessibility due to explicit mention or to activation from other sources (such as activation of conceptually related information in the larger discourse or non-linguistic information, like pictures and gestures; e.g., Clark and Marshall, 1981; Baumann and Hadelich, 2003; Kahn and Arnold, 2012). Accessibility of an event character can also be related to the notion of givenness.

Within the psycholinguistic tradition, evidence abounds that the accessibility of a referent influences production preferences, both in terms of speakers' choices of syntactic structures and the time-course of sentence formulation. For example, it has been repeatedly shown that speakers have a strong preference to begin sentences with accessible characters than less accessible characters (e.g., MacWhinney and Bates, 1978; Bock and Warren, 1985; Kempen and Hoenkamp, 1987; McDonald et al., 1993; Branigan and Feleki, 1999; Ferreira and Yoshita, 2003; Kempen and Harbusch, 2003; Christianson and Ferreira, 2005; Tanaka et al., 2011; Konopka and Meyer, 2014; Norcliffe et al., 2015; also see Gleitman et al., 2007, and Kuchinsky and Bock, 2010, for a discussion of perceptual accessibility). It is important to note, however, that these studies primarily examined sentence production out of context. Furthermore, accessibility in these studies is typically discussed in terms of the conceptual features of a referent (e.g., animate vs. inanimate referents), conceptual complexity (e.g., abstract vs. concrete concepts), and ease of naming (e.g., high-frequency vs. low-frequency words).

In addition, accessibility has been manipulated experimentally by increasing word activation levels via lexical primes (i.e., words that are semantically or associatively related to the target referents; Bock, 1986; Konopka and Meyer, 2014). The effect of both the inherent accessibility and experimentally manipulated accessibility of a referent on sentence planning is to facilitate and prioritize the encoding of that referent during the planning process: in eye-tracked production experiments, speakers quickly fixate easy-to-name referents, encode them as sentence subjects, and begin sentences with these references in subject position more quickly than sentences with harder-to-name referents
(Konopka and Meyer, 2014). Konopka (2014) provided further evidence that referent accessibility can have a similar effect on sentence planning. Participants described pictures of simple events (e.g., a frog catching a fly) with simple SVO sentences after reading a short sentence that provided either a neutral context or a supporting context for the upcoming target event and that mentioned either the agent or patient explicitly. The results showed that, when speakers produced active sentences, prior mention of the agent reduced not only the length of fixations on that referent but also speech onset in the descriptions that participants generated.

Accessibility can also be approached from the perspective of information integration in a discourse context, in particular the question of how existing information guides the processing of incoming information and how incoming information is in turn integrated with the preceding discourse context. Within the linguistic research tradition, various notions of information status have been posited, with two notably important, if not the most important, concepts: focus and givenness (but see Kruijff, 2001, for a review on various notions posited). A referent is "given" in a particular context if it has been linguistically mentioned and therefore constitutes shared knowledge or recoverable information in a specific context (e.g., Krifka, 2007, and Rochemont, 2016, for reviews). In addition, a referent is in "focus" in a discourse context when it provides new and/or alternative information and consequently advances the discourse (see Gussenhoven, 2007 and Krifka, 2007, for reviews).

There is some existing evidence in the literature that the planning of an utterance can be affected by the information status of individual referents in the to-be-articulated messages (e.g., whether the referents are new or known/given). For instance, Konopka (2013, 2014) and Ganushchak et al. (2014) showed that focus can affect the time-course of utterance planning. Ganushchak et al. (2014) asked participants to describe pictures of two-character transitive events in Dutch and Chinese, while their eye-movements were recorded. The information status of the characters to be encoded was manipulated by presenting wh-questions prior to each picture (e.g., What is the policeman stopping? Who is stopping the truck?). The results showed that speakers rapidly directed their gaze preferentially only to the new (i.e., focused) character they needed to encode before speech onset, suggesting a clear difference in the time-course of planning in sentences with focused and unfocused referents.

While Ganushchak et al. (2014) suggests that given and new characters are planned differently, we know little about how different levels of character accessibility affect sentence planning. In particular, there are at least two outstanding questions regarding the effect of different levels of accessibility (i.e., the degree to which information about event characters is accessible in a given context) on planning. First, it is not clear how levels of accessibility of a referent might affect sentence planning in a larger discourse context. Second, it is unclear whether different levels of accessibility of characters that are mentioned early vs. late in a sentence might affect planning in different ways.

To address these questions, we compared the time-course of formulation for simple SVO sentences after manipulating the degree of accessibility of the two event characters by simulating 
a real-life discourse context (Figure 1 and Examples 1-3). Participants' eye movements were tracked as they described pictures on a computer screen. The target descriptions were expected to have the same structure and content in all conditions (e.g., The frog catches the fly as most events elicited SVO descriptions). The accessibility of the agent (Experiment 1) and patient (Experiment 2) in each event was manipulated in three conditions by means of a short, two-sentence story presented before each picture. In the No Mention condition, the stories did not mention or prime either of the event characters. In the Literal condition, participants heard a story where either the agent (frog) or the patient $(f l y)$ was explicitly mentioned in a sentence that provided pragmatically appropriate, character-specific information (e.g., The frog jumped out of the pond). In the Associative condition, the agent or patient was not linguistically mentioned but the story conceptually primed activation of information related to the target character (e.g., the story included words such as quacking, pond, green, and jump), thereby increasing the accessibility of the target character.

Differences in the planning of the target sentences across conditions were evaluated by comparing speakers' eyemovements to the agents and patients in the picture prior to speech onset. When preparing to describe such pictures, speakers normally look at characters in the display in the order of mention (Griffin and Bock, 2000). However, there are still debates about the size of planning units during production, i.e., how much of a sentence the speaker typically plans before beginning to speak. Planning units have been shown to vary from units as large as an entire clause to being limited to a single phrase or word (see Konopka, 2012, for a review). Part of this variability can be due to variability in the ease of completing conceptual and linguistic processes required for sentence production.

Broadly speaking, incrementality in sentence planning can be either structural or lexical (Bock et al., 2003, 2004). Structural

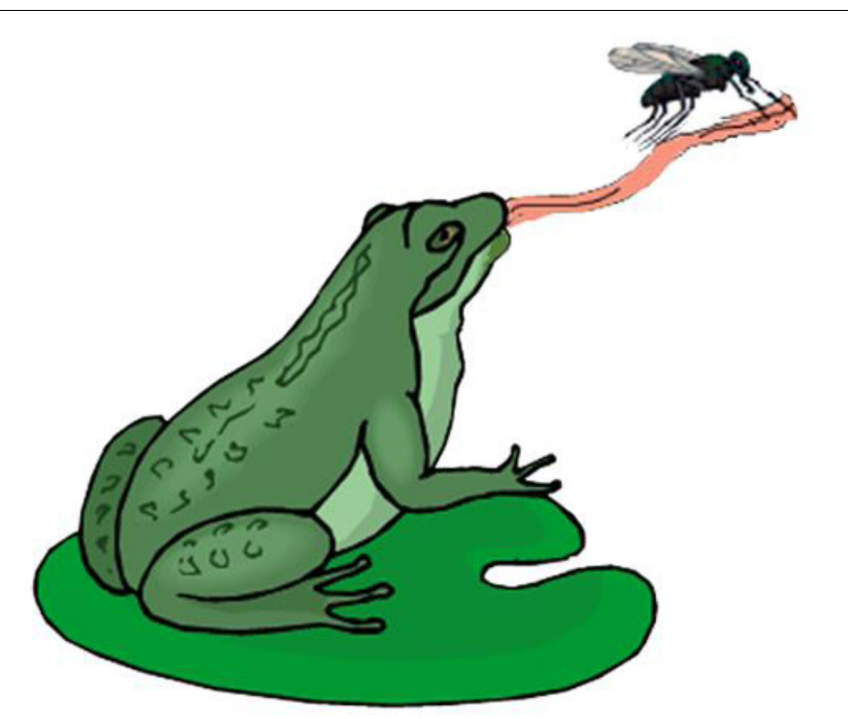

FIGURE 1 | Example of a target event. (or hierarchical) incrementality posits that sentence formulation begins with the generation of a simple but broad message and sentence plan that captures the relationship between various message elements (i.e., event characters; Bock et al., 2004; Konopka and Meyer, 2014). In some eye-tracking studies, formulation has been shown to begin with a short phase (0$400 \mathrm{~ms}$ ) during which fixations to the two characters do not differ or do not diverge rapidly (e.g., Griffin and Bock, 2000; Konopka, 2014). This pattern arguably indicates that speakers begin formulation by encoding (or apprehending) the gist of the entire event, suggesting that planning units at the message level can extend well beyond a single concept. Event apprehension is then followed by a longer phase of linguistic encoding during which speakers encode the character names sequentially. During linguistic encoding, easy-to-name characters are typically fixated for less time than harder-to-name characters (e.g., Meyer et al., 1998; Meyer and Lethaus, 2004; Konopka and Meyer, 2014). In contrast, lexical (or linear) incrementality predicts that a speaker plans the preverbal message one concept at a time and simultaneously plans the linguistic message of the sentence roughly one word at a time (e.g., Gleitman et al., 2007). Indeed, in similar eye-tracked production experiments, speakers have been shown to fixate the subject character very quickly after picture onset (before $400 \mathrm{~ms}$ ) and the length of fixations on this character also varied with the ease of encoding its name (Gleitman et al., 2007; Kuchinsky, 2009), indicating that, at least under some circumstances, speakers are able to start encoding the preverbal message as well as its linguistic content with one character alone (a very narrow scope of planning). In other words, linear incrementality assumes that speakers can prepare a sequence of small conceptual and linguistic increments without guidance from a higher-level framework.

The current study aims to provide further insight into how character accessibility can affect the scope and time-course of sentence planning. Our first hypothesis concerns eye movements observed immediately after picture onset (0-400 ms, i.e., in a time window associated with a combination of conceptual and linguistic encoding): effects of character accessibility on early eye movements (0-400 ms) should indicate to what extent information in the preceding discourse influences early planning strategies, i.e., the extent to which speakers engage in broad-scope, two-character message planning (hierarchical incrementality) or in narrow-scope, one-character planning (linear incrementality). Early differences in fixations to agents and patients in this window across conditions would indicate variability in when speakers begin encoding the agent in SVO sentences. For example, a higher proportion of early fixations to the agent would indicate a shift toward early encoding of this character. This would demonstrate sensitivity to properties of this character and thus sensitivity to context. If the accessibility of the two characters does not influence early formulation, there should then be no difference in gaze patterns across conditions.

A second hypothesis is that accessibility influences planning only at the linguistic encoding (sentence) level. Differences across conditions emerging after $400 \mathrm{~ms}$ (i.e., in time windows associated with linguistic encoding) would indicate that accessibility influences primarily how long it takes to encode a 
given character (i.e., the length of linguistic encoding), rather than when speakers begin encoding a given character (i.e., a shift in planning strategies). Here, a lower proportion of fixations to the agent as well as shorter fixations to this character indicate shorter lexical retrieval times (e.g., Griffin and Bock, 2000). If character accessibility influences linguistic encoding, then viewing patterns in the Literal and Associative conditions should differ from the No Mention condition: speakers should spend less time fixating the character that was mentioned or that was primed in the story, consistent with the finding that easy-toname characters are encoded more quickly than harder-to-name characters. Furthermore, fixations on the target character in the Literal condition should be shorter than in the Associative condition, since the name of this character is 'given' in the Literal condition but is only temporarily made more 'accessible' in the Associative condition.

Importantly, predictions from our hypotheses differ for conditions in which the agents versus the patients are "given" in the discourse. In the current experiments, linear incrementality predicts that only the accessibility of the first-mentioned agent (frog) should influence gaze patterns because the patient (fly) is planned in a separate increment. Thus fixations on the agent in Experiment 1 should vary across conditions, but there should be no differences in early fixations to the two event characters in Experiment 2. In contrast, hierarchical incrementality predicts that participants plan a larger preverbal message (a message that includes information about both the agents and patients) before beginning linguistic encoding, so there may be effects of character accessibility in both experiments. As with manipulations of the accessibility of the agent, fixations to the patient should be shorter in the Literal Patient condition than in the Associate and No Mention conditions in Experiment 2.

\section{EXPERIMENT 1: ACCESSIBILITY OF THE AGENT}

\section{Method \\ Participants}

Thirty native Dutch speakers (23 female) participated in the experiment (mean age: 21.2 years; $S D=1.6$ years). All participants were students at Dutch universities. The study was approved by the Ethical Committee board at Leiden University. Participants gave written informed consent and received course credit for their participation.

\section{Materials}

Seventy-eight colored pictures were used in the experiment (Konopka, 2014). All pictures displayed simple actions (Figure 1). There were 25 target pictures of transitive events, 50 fillers, and 3 practice pictures. All target pictures had human/animate agents, and thus elicit primarily SVO descriptions. Thirteen out of 25 pictures also had a human/animate patient.

Accessibility was manipulated by means of short stories preceding each picture. All stories consisted of two sentences and were contextually related to the pictures in the three conditions manipulated in the experiment. Take the expected target sentence De kikker vangt de vlieg ('The frog catches the fly') as an example. The stories presented in the three conditions before picture presentation are listed below:

(1) No Mention condition: The story did not mention the words describing the intended target character or include associatively related words.

David gaat met zijn vader vissen. Ze gebruiken restjes van het avondeten als aas. (David is going fishing with his father. They use leftovers from dinner as bait.)

(2) Literal condition: The agent was explicitly mentioned in the second sentence of the story and in the same grammatical role as in the intended target sentence.

David gaat met zijn vader vissen. Een kikker springt opeens in de sloot. (David is going fishing with his father. A frog suddenly jumped into the ditch.)

(3) Associative condition: The story primed the intended agent. All stories were pre-tested: 20 undergraduate students from Leiden University read all 30 stories one by one and were asked to write down the first word that came to mind after reading each story. The 25 stories with the highest agreement on the intended target word were chosen for the main experiment (agreement $>80 \%$ ).

Koen hoort gekwaak bij de vijver. Als hij gaat kijken, ziet hij iets groens wegspringen. (Koen heard quacking near the pond. When he went to look, he saw something green jumping away.)

All stories were pre-recorded by a native Dutch female speaker and presented auditorily prior to picture onset in the experiment. On $40 \%$ of the filler trials, participants received and answered a yes-or-no comprehension question, presented visually on the computer screen before receiving a picture to describe, to make sure that they listened carefully to the presented stories.

\section{Design and Procedure}

Lists of stimuli were created to counterbalance story type across target pictures within participants and within items. Each target picture occurred in each condition on a different list so that each participant saw each picture only once. There were at least two filler pictures separating any two target trials in each list.

Participants were seated in a sound-proof room. Eye movements were recorded with an Eyelink 1000 eye-tracker (SR Research Ltd.; $500 \mathrm{~Hz}$ sampling rate). A 9-point calibration procedure was performed at the beginning of the experiment. All picture trials began with a fixation point presented at the top of the screen for drift correction. The task started with three practice trials. On all trials, participants first heard a story (presented through headphones). The participants were instructed to listen carefully to the story as sometimes they would be asked a question about it immediately after reading the story. On 40\% of the filler items, participants received a yes/no comprehension question and where instructed to use the computer mouse to give their response. The stories were followed by presentation of the pictures that participants had to describe out loud with one 
sentence, mentioning all the characters in the picture. They were not under time pressure to produce the descriptions and were not instructed to produce sentences with any specific structure. They were also not told about the relationship between the stories and the pictures. When the participant finished speaking, the experimenter clicked with the mouse to proceed to the next trial. On average, the pictures were displayed on the screen for $5227 \mathrm{~ms}$ $(S D=1604 \mathrm{~ms})$.

\section{Scoring and Data Analysis}

Trials in which the first fixation was within the agent or patient interest area instead of the fixation point at the top of the screen were removed from further analysis (2\% of the data). Only sentences with active (SVO) and passive (OVS) structures were scored as correct, but the analyses were limited to active sentences. Thus all trials with passive descriptions, incomplete descriptions (e.g., not naming or incorrectly naming one of the characters), or corrections during the description were excluded from further analysis (Literal: 6.3\%; Associative: 9.3\%; No Mention: 7.2\%). Speech onset latencies shorter or longer than two standard deviations were also removed from the analysis ( $0.9 \%$ of the data). This left 672 trials for analysis.

Analyses were first carried out on speech onsets after applying a log transformation to remove the intrinsic positive skew of RT distributions (Baayen et al., 2008). Mixed-effects models were run with participants and items as random effects, Condition (Literal, Associative, and No Mention) as a fixed effect, and by-subject and by-item random slopes for Condition. The three conditions were compared with two contrasts using treatment coding. The first contrast compared the No Mention condition against the Literal condition. The second contrast compared the No Mention condition against the Associative condition. Both contrasts thus assessed how planning a sentence in response to a story that mentions one of the event characters changed response latencies relative to the No Mention condition. Finally, separate analyses were run with new contrasts to compare speech onsets in the Literal and Associative conditions.

The time-course of sentence formulation in the three conditions was compared with by-participant $\left(\beta_{1}\right)$ and byitem $\left(\beta_{2}\right)$ quasi-logistic regression analyses performed on agentdirected fixations (Barr, 2008). We selected two time windows (0-400 ms and 400-1400 ms) for analysis, consistent with earlier analyses of eye movement patterns during spontaneous production of similar descriptions. Fixations were aggregated into a series of time bins of $200 \mathrm{~ms}$ for each participant and each item in each condition ${ }^{1}$. The dependent variable in each time bin was an empirical logit indexing the likelihood of speakers fixating the agent out of the total number of fixations observed in that time bin. Time and Condition were entered as fixed effects into all models. All models also included random by-participant and by-item intercepts and slopes for the Time and Condition variables. Main effects in these analyses indicate differences across conditions in the first bin of each window. Interactions with Time

\footnotetext{
${ }^{1} \mathrm{We}$ also run analysis with the smaller bins, which resulted in the same results. We chose to report a more conservative analysis with $200 \mathrm{~ms}$ bins.
}

show how fixation pattern changed over the remaining bins in that time window.

Similarly to the speech onset analyses, fixations in the three conditions were compared with two contrasts (the No Mention condition against the Literal and Associative conditions separately), and the Literal and Associative conditions were then compared in a separate analysis.

\section{Results}

\section{Speech Onsets}

No significant differences were found in speech onset latencies between the Literal, Associative, and No Mention conditions (all ts $<1.5$; see Table 1 for means).

\section{Time-Course of Sentence Formulation}

Figures $2 \mathrm{~A}-\mathrm{C}$ shows the proportions of fixations to the agent and patients in target pictures across the three conditions. Figure $4 \mathbf{A}$ plots the proportions of fixations to the agent in the target pictures for each condition.

TABLE 1 | Mean response latencies in $\mathrm{ms}$ (with standard deviation) per condition in Experiment 1 (manipulating Agent Accessibility) and in Experiment 2 (manipulating Patient Accessibility).

\begin{tabular}{lccc}
\hline & $\begin{array}{c}\text { Literal } \\
\text { Mention }\end{array}$ & $\begin{array}{c}\text { Associative } \\
\text { Mention }\end{array}$ & $\begin{array}{c}\text { No } \\
\text { Mention }\end{array}$ \\
\hline Experiment 1 & $1841(489)$ & $1874(551)$ & $1866(496)$ \\
Experiment 2 & $1882(628)$ & $1944(519)$ & $1895(508)$ \\
\hline
\end{tabular}
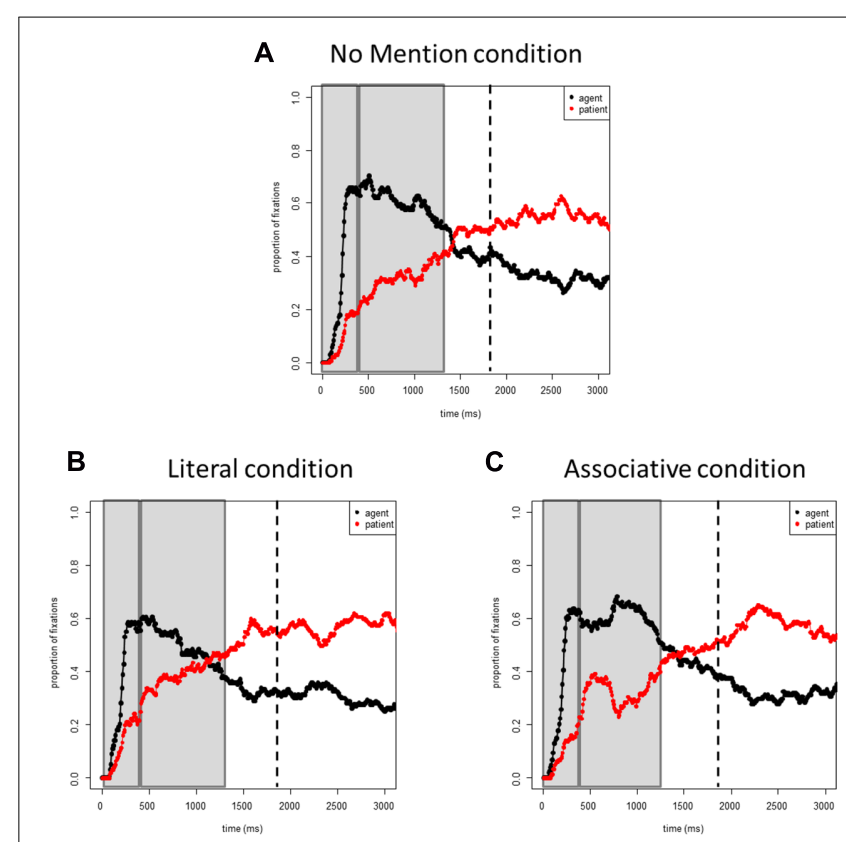

FIGURE 2 | Experiment 1 (Agent Accessibility). Proportions of fixations to the agents and patients in the target event pictures: (A) No Mention condition, (B) Literal condition, (C) Associative condition. Time 0 corresponds to picture onset in all figures. Dashed lines represent speech onset. Areas selected by rectangles depict the two time windows (0-400 and 400-1400 ms) used in the analyses. 


\section{0-400 ms}

In all conditions, speakers rapidly directed their gaze to the agent in the picture (main effect of Time: $\beta_{1}=6.09, \beta_{2}=6.07$, both ts $>19$ ), suggesting linearly incremental planning. Neither the main effects of Condition nor the interactions with Condition in this time window were significant (all $t s<1$ ).

\section{$400-1400 \mathrm{~ms}$}

After $400 \mathrm{~ms}$, there were fewer fixations to the agent in the Literal condition than in the No Mention condition $\left(\beta_{1}=0.42\right.$, $\beta_{2}=0.35$, both $t \mathrm{~s}>2.9$ ). Speakers were also somewhat less likely to fixate the agent in the Associative condition than in the No Mention condition. However, this effect reached significance only in the by-subject analysis $\left(\beta_{1}=-0.26, t<-1.99 ; \beta_{2}=-0.14\right.$, $t<-1.3$ ), which is likely due only to the small and transient difference between conditions observed between 400 and $800 \mathrm{~ms}$. Comparing the Literal and Associative conditions against one another in a separate analysis showed that there were fewer looks to the agent in the Literal condition than in the Associative condition ( $\beta_{1}=-0.39, \beta_{2}=-0.23$, both $t$ s $\left.<-2.4\right)$. Including an interaction between Time and Condition did not improve model fits relative to the additive models $\left(\chi^{2}=0.89, p>0.05\right)$.

\section{Discussion}

In all three conditions, speakers fixated characters in the order of mention: first the agent (e.g., frog) and then the patient (e.g., $f l y)$. Gaze shifts to the patient occurred prior to speech onset. This pattern generally replicates earlier findings (e.g., Griffin and Bock, 2000), but more specifically, the sharp rise of gaze fixation proportions to the agent within the $0-400 \mathrm{~ms}$ window is more consistent with linearly than structurally incremental planning (Gleitman et al., 2007; Kuchinsky, 2009).

The results also show that during the earliest stages of formulation (0-400 ms), character accessibility did not exert an influence on the allocation of attention to the two event characters. This is in line with previous findings showing that information status (i.e., whether information is new and therefore focused or not) does not affect early planning strategies (e.g., Ganushchak et al., 2014). In the present study, eye movements were affected by character accessibility only in later time windows (i.e., after $400 \mathrm{~ms}$ ). We expected speakers to have a strong preference to fixate the new, and thus not accessible, character in the event with priority (No Mention condition) and for the length of fixations on this character to vary depending on the discourse context in the remaining conditions (Literal and Associative conditions). As predicted, there were fewer agentdirected fixations in the Literal condition, where the agent was fully given than in the No Mention condition in the second time window (400-1400 ms). The Associative condition, which in terms of character accessibility lies in between the Literal and No Mention condition, showed little difference from the No Mention condition.

Thus, how does accessibility influence the time-course of formulation? In all three conditions, the planning of the message and sentence occurred in a highly incremental manner, consistent with linear incrementality. As we discussed earlier, when speakers first see a picture of an event, they can choose to either "explore" the entire picture to encode its gist (hierarchical planning) or immediately focus on one character in the picture and start building a sentence with that character in subject position (linear planning). Hierarchical planning begins with a convergence of fixations to agents and patients immediately after picture onset (the 0-400 ms time window; Griffin and Bock, 2000 and Konopka and Meyer, 2014, under some conditions). Linear planning begins with a clear divergence of fixations to agents and patients within $200 \mathrm{~ms}$ of picture onset and is followed by an extended window with subject fixations (Gleitman et al., 2007). As shown in multiple studies since Meyer et al. (1998), speakers carry out linguistic encoding during such extended fixations to a particular entity (also see Griffin, 2001, 2004; Meyer and Lethaus, 2004; and many others). Our results suggest highly linear incremental planning: speakers fixated the subject character with priority very quickly after picture onset, which implies that they were encoding primarily this character conceptually and linguistically, while the large shift of gaze to the object character around speech onset marks the much later onset of conceptual and linguistic encoding for this character.

Effects of accessibility were observed only at the level of linguistic encoding. In the Literal condition, there was a significant reduction of fixations to the agent from $400 \mathrm{~ms}$ onward, compared to that in the No Mention and Associative conditions. This reduction can be explained by the fact that in the Literal condition, the agent was explicitly mentioned in the preceding context, thereby reducing the costs of retrieving the lexical and phonological form of this character name (e.g., Ganushchak et al., 2014; Konopka, 2014). In the Associative condition, speakers also showed a small and transient reduction in fixations to the agent compared to the No Mention condition. This reduction was weaker than in the Literal condition, presumably due to the fact that the agent was only activated conceptually by the preceding discourse and the speaker still needed to encode a character name at the lexical and phonological level. This pattern is also in line with the small delay in the onset speech latency in this condition: although this effect did not reach significance, the general trend is that speakers started speaking later in the Associative condition than in the other two conditions. This is consistent with the previous literature showing that linguistically given referents had a substantially larger effect on production (e.g., larger acoustic changes) than non-linguistically given referents (e.g., Baumann and Hadelich, 2003; Kahn and Arnold, 2012). To conclude, our results did show that sentence planning in a discourse context can be affected by the degree of character accessibility. On the one hand, there is a clear difference between the Literal condition and the No Mention condition, which shows that linguistically mentioned referents can facilitate planning of the utterance. On the other hand, the difference between the Associative and No Mention condition was small, suggesting that the referents that are not linguistically mentioned but are only conceptually accessible (Associative condition) are planned in a similar way to referents that are neither linguistically given nor conceptually accessible (No Mention condition). This would suggest that what matters more during linguistic encoding is whether a referent is linguistically given or not (i.e., conceptual accessibility without 
linguistic mention is not sufficient to produce a difference in the time-course of planning).

In Experiment 2, we examine whether utterance planning is affected by the different levels of accessibility of the patient as well.

\section{EXPERIMENT 2: ACCESSIBILITY OF THE PATIENT}

\section{Method}

\section{Participants}

Thirty-one new native Dutch speakers (28 women) participated in the experiment (mean age: 20 years; $S D=1.9$ years) from the same participant pool as in Experiment 1. Due to a technical problem, data of one participant was excluded from the analysis.

\section{Materials, Design, Procedure, and Data Analysis}

The materials were similar to the ones in Experiment 1, with the difference that the patient rather than the agent was literally mentioned (the Literal condition) or primed (the Associative condition) in the stories that preceded the pictures. The No Mention condition was identical in both experiments (see below for examples of the stories).

(1) No Mention condition: The story did not mention the words describing the target character or include associatively related words.

David gaat met zijn vader vissen. Ze gebruiken restjes van het avondeten als aas. (David is going fishing with his father. They use leftovers from dinner as bait.)

(2) Literal condition: The patient was explicitly mentioned.

David vist regelmatig en weet dus ook het een en ander over vissen. Hij gebruikt een kleine vlieg als aas. (David goes fishing often and knows a lot about fishing. He uses a small fly as bait.)

(3) Associative condition: The story primed activation of the intended target word. Similar to Experiment 1, stories with the highest agreement on the intended target word were chosen from the pilot study for the main experiment (agreement $>80 \%$ ).

In de zomer zijn er meer insecten in de natuur. Sommige zijn zwart en hebben vleugels. (During summer, there are a lot of insects in nature. Some are black with wings.)

The design, procedure and analyses were identical to Experiment 1. The target pictures remained on the screen for an average of $4467 \mathrm{~ms}(S D=1263 \mathrm{~ms})$. Target trials on which erroneous responses were given were removed from further analysis (Literal: 7.7\%; Associative: $8.8 \%$; No Mention: $7.1 \%$ ). In addition, $1.5 \%$ of trials were removed because the first fixation was within the agent or patient interest area instead of the fixation point. This left 696 trials for analysis.

\section{Results}

\section{Speech Onsets}

There were no significant differences in speech onset latencies between the Literal, Associative, and No Mention conditions (all ts $<1.7$; see Table 1 for means).

\section{Time-Course of Sentence Formulation}

Figures $\mathbf{3 A - C}$ shows the proportions of fixations to the agent and patients in target pictures across conditions. Figure $\mathbf{4 B}$ plots the proportions of fixations only to the agent in the target pictures for each condition.

\section{$0-400 \mathrm{~ms}$}

No main effects or interactions were significant (all $t s<1$ ).

400-1400 ms

No main effects or interactions were significant (all $t \mathrm{~s}<1.1$ ).

\section{Discussion}

In Experiment 2, participants again looked at the event characters in the order of mention. However, contrary to the findings of Experiment 1, the accessibility of the patient, manipulated in the preceding discourse context, did not affect early $(0-400 \mathrm{~ms})$ or late (400-1400 ms) gaze patterns.

What might explain the lack of effects of Condition (i.e., patient accessibility) on formulation in the current study? One possibility is that effects of accessibility of the patient may be observed only at the level of structure choice. There is ample evidence that speakers have a strong preference to begin their sentences with accessible characters. In the current experiment,

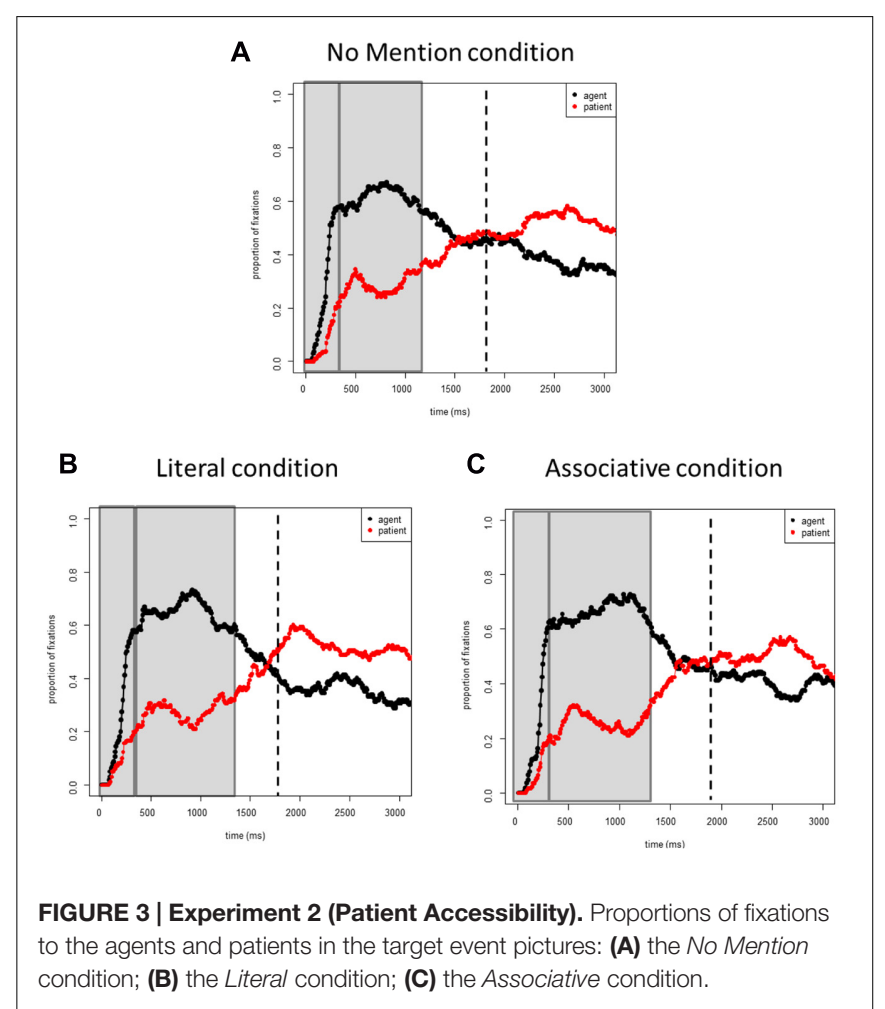




\section{A}

Experiment 1: Agent Accessibility

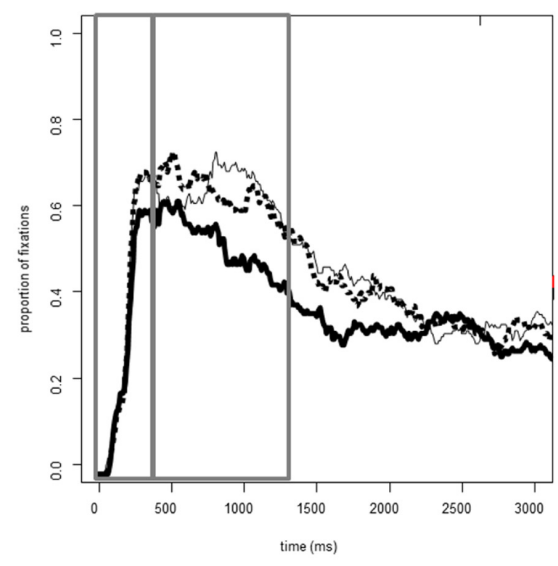

B $\quad$ Experiment 2: Patient Accessibility

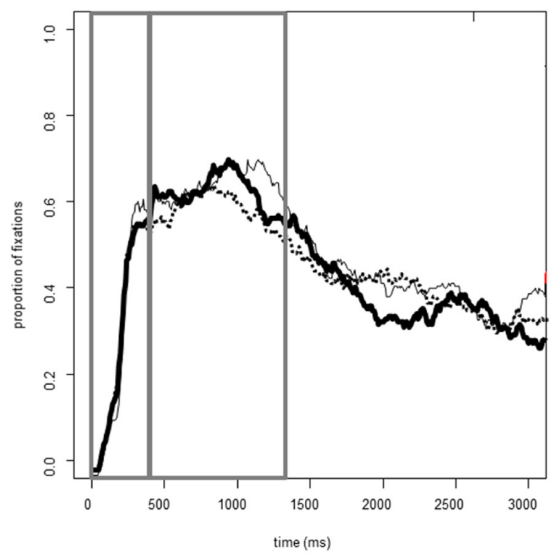

....... No Mention condition

— Literal condition

_ Associative condition

FIGURE 4 | Proportions of fixations to the agents in target event pictures across all conditions: (A) Experiment 1 (Agent Accessibility); (B) Experiment 2 (Patient Accessibility).

patients were more accessible in the Literal and Associative conditions and hence should have been more likely to become sentence subjects than in the No Mention condition (where the patient was less accessible as it was not given in the discourse). Speakers did indeed produce more sentences with the intended patient in subject position in the Literal (2.2\%) and Associative (2.5\%) conditions than in the No Mention condition (1\%), but production of such sentences was too infrequent to allow statistical analysis.

At the level of sentence formulation, a possible reason for the lack of an effect of Condition is that speakers were planning the utterance in a very linearly incremental fashion. As in Experiment 1 , they started formulation by encoding only the agent with priority. Thus, by the time they started to encode the patient (possibly after starting to speak), the degree of accessibility of the patient was of little consequence for the planning of the sentence. At present, it is also difficult to identify differences in patterns of fixations to a character produced relatively late in a sentence due to increasing variability in the data with each time bin. These results differ from earlier studies which did show that explicit mention of a patient in a question preceding the target pictures (Who is stopping the truck?) reduced the costs of retrieving its name as well as the length of fixations on this character (e.g., Konopka, 2013; Ganushchak et al., 2014). Thus, a second reason for the lack of a patient accessibility effect could be the nature of the discourse context itself. Ganushchak et al. (2014) asked wh-questions before showing speakers events to describe. The questions set up a context that was clearly related to either the agent or the patient of the event. Thus, for the speakers, it was clear what information mentioned in the preceding context should be part of their response. In the present study, however, participants heard short stories that did not provide unambiguous and consistent cues as to which concepts from the preceding discourse would be part of the upcoming, tobe-produced sentence. In addition, speakers might have tried to suppress activation of information related to the patient from the preceding context in order to start planning sentences beginning with the agent (i.e., active, SVO sentences). This is supported by the somewhat longer speech onset latencies in Experiment 2 compared to Experiment $1^{2}$.

Finally, in our study, items were strongly biased toward events that elicit SVO sentences. As mentioned earlier, 100\% of our target pictures had human/animate agents, and only 52\% had human/animate patients. Speakers tend to produce SVO sentences when the agent is human/animate and when the agent and patient are of similar animacy, and are thus reluctant to use non-canonical structures (e.g., Bock et al., 1992; Ferreira, 1994; Branigan et al., 2008). Importantly, however, even in the absence of an effect of context on sentence structure, there are differences in the time-course of formulation (see below for a joint analysis of the data in Experiments 1 and 2). Further research is needed to examine what factors modulate the effect of accessibility of characters that are not produced in sentence-initial position on sentence planning.

\footnotetext{
${ }^{2}$ Note that similar to our study, in Konopka and Meyer's (2014) study, participants were also unaware which of the event characters was primed by the preceding context. But they did report that object primes influenced structure choice in planning, which is likely, at least partly, due to the selection of events that were more likely to elicit OVS descriptions.
} 
Overall, our results show that the conceptual and linguistic planning of a patient occurs possibly as late as after speech onset. This is consistent with the prediction that, since only the first phrase of the sentence is planned conceptually and linguistically prior to articulation, only the availability of lexical items produced in that initial phrase (i.e., the agent name) influences planning at this stage. Allum and Wheeldon (2007, 2009) showed a similar effect in experiments where participants previewed pictures of objects (e.g., a flower) that they were to use in a subsequent sentence (e.g., The flower above the dog is red; The dog above the flower is red). In these studies, speech onsets were shorter only when the sentence-initial picture was previewed but not when participants previewed a picture whose name was produced in the second phrase. Similarly, Griffin (2001) showed that, when producing highly schematic sentences like The $A$ and the $B$ are above the $C$, speech onsets and gaze durations on the first object were unaffected by properties of the second object. Finally, Schriefers et al. (1998) showed that verb retrieval occurred before sentence onset only when the verb was produced in sentenceinitial position. Such findings suggest that the linguistic planning of content words in simple sentences indeed occurs in a highly linearly incremental way in sentences with repeated syntactic structures.

\section{Experiment 1 vs. Experiment 2}

Finally, we assessed differences between the accessibility of agents and patients on utterance formulation in a joint analysis for Experiments 1 and 2. In these analyses, the fixed factor Experiment was added into all the models and the analyses were carried out as described above (i.e., Time and Condition were entered as fixed effects into all models; all models also included random by-participant and by-item intercepts and slopes for the Time and Condition variables.). The log-likelihood ratio test $\left(\chi^{2}\right)$ was used to compare model fits in interactive and additive models, and thus test whether interactions with the Experiment variable significantly improved model fit. A reliable difference in this comparison indicates a better fit for the interactive model than the additive model.

\section{0-400 ms}

There was no difference between Experiment 1 and Experiment 2 (all interactions with Experiment: $t \mathrm{~s}<1$ ). In addition, adding the Experiment variable into the model did not improve model fit relative to a model without this variable $\left(\chi^{2}=1\right)$.

\section{0-1400 ms}

For all of the models, adding Experiment as a fixed factor significantly improved model fit $\left(\chi^{2}<0.01\right)$, and there was a significant interaction between Experiment and Time for all contrasts (Literal vs. Associative: $\beta_{1}=-0.44, \beta_{2}=-0.34$, both ts $<-3.0$; Literal vs. No Mention: $\beta_{1}=-0.46, \beta_{2}=-0.37$, both ts $<-3.0$; Associative vs. No Mention: $\beta_{1}=-0.48, \beta_{2}=-0.42$, both $t$ s $<-3.0$ ). Overall, there were more looks to the agent in Experiment 2 (manipulating accessibility of the patient) than in the Experiment 1 (manipulating accessibility of the agent). Additionally, the comparison between the Literal and No Mention conditions showed a significant interaction between Experiment and Condition $\left(\beta_{1}=0.53, \beta_{2}=0.45\right.$, both $t$ s $\left.<-3.3\right)$, as there were fewer looks to the agent in the Literal condition in Experiment 1 than in Experiment 2. This confirms that changes in agent-directed fixations were driven by the degree of accessibility of the referent.

\section{GENERAL DISCUSSION}

In two experiments, we compared the time-course of formulation for sentences produced when two event characters (agents and patients) varied in terms of their contextual accessibility. The discourse context either provided no information about the target event (No Mention condition), specifically mentioned one of the event characters (Literal Agent and Patient conditions), or was associatively related to one of the characters (Associative Agent and Patient conditions).

The results showed that character accessibility did not influence the distribution of attention to the two event characters immediately after picture onset (0-400 ms) but only later, after $400 \mathrm{~ms}$. Thus, the discourse manipulation did not affect when speakers began encoding a given character, but rather affected the length of time needed to encode that character. Overall, only the accessibility of the agent (i.e., the sentence-initial character) and not the accessibility of the patient (i.e., the sentence-final character) affected gaze patterns, suggesting linearly rather than hierarchically incremental planning.

This suggests that information activated by the discourse context (conceptual, lexical, and phonological information in the Literal condition; conceptual information in the Associative condition) can facilitate planning but only when it is relevant for the initial word/phrase of the sentence. Our results show that the planning of the patient occurred after planning of the agent, likely around speech onset, and thus was not part of the initial preverbal message generated at picture onset. We conclude that when the discourse activates information that is relevant for phrases further downstream (i.e., after the sentence-initial word/phrase), it is less beneficial for planning since it falls outside the scope of the first planning window. This is in line with previous findings that showed that effects of lexical activation are limited only to the production of a sentence-initial word (e.g., Meyer, 1996; Wheeldon and Lahiri, 1997; Griffin, 2001; Costa et al., 2006; Allum and Wheeldon, 2007, 2009). The exact timing of the planning of the patient relative to speech onset may vary with the ease of encoding the agent: rapid encoding of the agent likely allows an earlier shift of gaze and attention to the patient (as in Experiment 1), while slower encoding of the agent likely results in a delayed shift of gaze and attention to the patient (as in Experiment 2). The difference in timing between the shift of gaze to the patient and speech onset across experiments may suggest a change in late planning strategies that deserves further attention in future work.

Finally, the discourse context in the present study was not intended to help participants understand the gist of the depicted events, although we cannot exclude the possibility that it provided conceptual information that facilitated gist encoding. Furthermore, we cannot exclude the possibility that the fact 
that the structure of to-be-produced sentences was repeated in Experiments 1 and 2 led to more linear planning than would have been the case when structure was not repeated (e.g., Konopka and Kuchinsky, 2015). For instance, Konopka and Kuchinsky (2015) used conceptual and structural primes before asking participants to describe target events (similar to the Associative and No Mention conditions in the present study), and found that both types of primes jointly affected the formulation of target descriptions on both the message and sentence levels, albeit with much stronger effects at the sentence level. It is possible that event gist was also primed by the discourse context in our study but that it did not influence formulation due to repeated production of one sentence type (SVO).

A final theoretical question concerns the difference between accessibility and givenness. Hypothetically, one could reduce the effect of discourse accessibility in these experiments to mere lexical priming and thus attribute the observed differences between conditions to differences in levels of word activation, or linguistic givenness. Givenness in the existing linguistic literature has often been operationalized as a binary classification of a referent being either given or new (but see Chafe, 1976; Ariel, 1990; Gundel et al., 1993), and a referent is defined as being "given" in a particular context specifically if it has been linguistically mentioned. Givenness has been shown to influence, for example, the form of referential expressions and their acoustic/phonetic realization: referential expressions used for known referents tend to be shorter and have different intonation contours (e.g., Brown, 1983; Pierrehumbert and Hirschberg, 1990; Baumann, 2006; Chen, 2010; see also Ladd, 2008; Baumann and Riester, 2012, for further discussion and references). Listeners have also been shown to be sensitive to the various prosodic cues that speakers employ to signal different levels of givenness (Baumann and Grice, 2006).

In our study, the givenness of a referent was operationalized as accessibility at two levels of that referent's representation, namely accessibility at the conceptual level (in the Associative condition) and accessibility at the linguistic level (in the Literal condition). Our results show that different levels of accessibility affected planning in different ways, and while more research is needed to identify the mechanism(s) behind effects of lexical primes and discourse primes on sentence formulation, we propose that givenness can also be viewed beyond the given vs. not given dichotomy. Instead, it may, and probably should, be viewed as a variable that, together with accessibility, expresses differences in the activation of a referent during conceptual and linguistic planning.

\section{REFERENCES}

Allum, P. H., and Wheeldon, L. R. (2007). Planning scope in spoken sentence production: the role of grammatical units. J. Exp. Psychol. 33, 791-810. doi: 10.1037/0278-7393.33.4.791

Allum, P. H., and Wheeldon, L. R. (2009). Scope of lexical access in spoken sentence production: implications for the conceptual-syntactic interface. J. Exp. Psychol. 35, 1240-1255. doi: 10.1037/a0016367

Ariel, M. (1990). Accessing Noun-Phrase Antecedents. London: Routledge.

\section{CONCLUSION}

Our results show that sentence planning can be affected by the relative accessibility of event characters, such that in situations where the discourse context does not provide clear cues about the sequential position of these concepts in a potential utterance, character accessibility impacts sentence formulation only when the accessible character is mentioned in sentence-initial position.

\section{ETHICS STATEMENT}

The study was approved by the ethical committee board at Leiden University. All participants were adults. At the beginning of the experimental session, they read the instructions describing the experiment and were asked whether they are happy to proceed. The instruction describes the task and structure of the experiment. The instructions stress that the participant is free to leave the experiment at any time without providing any explanation to the experimenter. If the participant is happy to proceed, they sign the consent form and the experiment commences. If a person decides not to participate, the experimenter will reassure him/her that this is entirely acceptable and thank him/her for his/her interest.

\section{AUTHOR CONTRIBUTIONS}

LG: Substantial contributions to the conception or design of the work; the acquisition, analysis, and interpretation of data for the work; drafting the work and revising it critically. AK: Substantial contributions to the design of the work; interpretation of data for the work; critically revising the manuscript. YC: Substantial contributions to the conception or design of the work; interpretation of data for the work; critically revising the manuscript. LG, AK, and YC: Final approval of the version to be published; agreement to be accountable for all aspects of the work in ensuring that questions related to the accuracy or integrity of any part of the work are appropriately investigated and resolved.

\section{ACKNOWLEDGMENTS}

We thank Phoebe Ye and Gouming Martens for help with data collection for Experiment 1 and 2, respectively. This research was supported by the European Research Council for the ERC Starting Grant (206198) to YC.

Baayen, R. H., Davidson, D. J., and Bates, D. M. (2008). Mixed-effects modeling with crossed random effects for subjects and items. J. Mem. Lang. 59, 390-412. doi: 10.1016/j.jml.2007.12.005

Barr, D. J. (2008). Analyzing 'visual world' eyetracking data using multilevel logistic regression. J. Mem. Lang. 59, 457-474. doi: 10.1016/j.jml.2007.09.002

Baumann, S. (2006). The Intonation of Givenness-Evidence From German (Linguistische Arbeiten 508). Tübingen: Niemeyer. doi: 10.1515/9783110921205 Baumann, S., and Grice, M. (2006). The intonation of accessibility. J. Pragmat. 38, 1636-1657. doi: 10.1016/j.pragma.2005.03.017 
Baumann, S., and Hadelich, K. (2003). “Accent type and givenness: an experiment with auditory and visual priming," in Proceedings of the 15th ICPhS, Barcelona, 1811-1814.

Baumann, S., and Riester, A. (2012). "Referential and lexical givenness: semantic, prosodic and cognitive aspects," in Prosody and Meaning, eds G. Elordieta and P. Prieto (Berlin: Mouton De Gruyter), 119-162.

Bock, J. K. (1986). Meaning, sound, and syntax: lexical priming in sentence production. J. Exp. Psychol. 12, 575-586. doi: 10.1037/0278-7393.12.4.575

Bock, J. K., Irwin, D. E., and Davidson, D. J. J. (2004). "Putting first things first," in The Integration of Language, Vision, and Action: Eye Movements and the Visual World, eds F. Ferreira and M. Henderson (New York, NY: Psychology Press), 249-278.

Bock, J. K., Loebell, H., and Morey, R. (1992). From conceptual roles to structural relations: bridging the syntactic cleft. Psychol. Rev. 99, 150-171. doi: 10.1037/ 0033-295X.99.1.150

Bock, J. K., and Warren, R. K. (1985). Conceptual accessibility and syntactic structure in sentence formulation. Cognition 21, 47-67. doi: 10.1016/00100277(85)90023-X

Bock, K., Irwin, D. E., Davidson, D., and Levelt, W. J. M. (2003). Minding the clock. J. Mem. Lang. 48, 653-685. doi: 10.1016/S0749-596X(03)00007-X

Branigan, H. P., and Feleki, E. (1999). "Conceptual accessibility and serial order in Greek language production," in Proceedings of the 21st Conference of the Cognitive Science Society, Vancouver, 96-101.

Branigan, H. P., Pickering, M. J., and Tanaka, M. (2008). Contributions of animacy to grammatical function assignment and word order during production. Lingua 118, 172-189. doi: 10.1016/j.lingua.2007.02.003

Brown, G. (1983). "Prosodic structure and the given/new distinction," in Prosody: Models and Measurements, eds A. Cutler and R. Ladd (Berlin: Springer Verlag), 67-77. doi: 10.1007/978-3-642-69103-4_6

Chafe, W. L. (1976). "Givenness, contrastiveness, definiteness, subjects, topics, and point of view," in Subject and Topic, ed. C. N. Li (New York, NY: Academic Press), 25-56.

Chen, Y. (2010). Post-focus f0 compression-Now you see it, now you don't. J. Phon. 38, 517-525. doi: 10.1016/j.wocn.2010.06.004

Christianson, K., and Ferreira, F. (2005). Conceptual accessibility and sentence production in a free word order language (Odawa). Cognition 98, 105-135. doi: 10.1016/j.cognition.2004.10.006

Clark, H. H., and Marshall, C. R. (1981). "Definite reference and mutual knowledge," in Elements of Discourse Understanding, eds A. K. Joshi, B. L. Webber, and I. S. Sag (New York, NY: Cambridge University Press), 10-63.

Costa, A., Navarrete, E., and Alario, F. X. (2006). Accessing object names when producing complex noun phrases: implications for models of lexical access. Cognitiva 18, 3-23. doi: 10.1174/0214355067754 62454

Ferreira, F. (1994). Choice of passive voice is affected by verb type and animacy. J. Mem. Lang. 33, 715-736. doi: 10.1006/jmla.1994.1034

Ferreira, V. S., and Yoshita, H. (2003). Given-new ordering effects on the production of scrambled sentences in Japanese. J. Psycholinguist. Res. 32, 669692. doi: 10.1023/A:1026146332132

Ganushchak, L. Y., Konopka, A., and Chen, Y. (2014). What the eyes say about planning of focused referents during sentence formulation: a crosslinguistic investigation. Front. Psychol. 5:e1124. doi: 10.3389/fpsyg.2014. 01124

Gleitman, L., January, D., Nappa, R., and Trueswell, J. C. (2007). On the give and take between event apprehension and utterance formulation. J. Mem. Lang. 57, 544-569. doi: 10.1016/j.jml.2007.01.007

Griffin, Z. M. (2001). Gaze durations during speech reflect word selection and phonological encoding. Cognition 82, B1-B14. doi: 10.1016/S0010-0277(01) 00138-X

Griffin, Z. M. (2004). The eyes are right when the mouth is wrong. Psychol. Sci. 15, 814-821. doi: 10.1111/j.0956-7976.2004.00761.x

Griffin, Z. M., and Bock, J. K. (2000). What the eyes say about speaking. Psychol. Sci. 11, 274-279. doi: 10.1111/1467-9280.00255

Gundel, J. K., Hedberg, N., and Zacharski, R. (1993). Cognitive status and the form of referring expressions. Language 69, 274-307. doi: 10.2307/416535

Gussenhoven, C. (2007). "Types of focus in English," in Topic and Focus: CrossLinguistic Perspectives on Meaning and Intonation, eds C. M. Lee, M. Gordon, and D. Büring (Dordrecht: Springer), 83-100. doi: 10.1007/978-1-40204796-1_5

Kahn, J. M., and Arnold, J. E. (2012). A processing-centered look at the contribution of givenness to durational reduction. J. Mem. Lang. 67, 311-325. doi: 10.1016/j.jml.2012.07.002

Kempen, G., and Harbusch, K. (2003). Word order scrambling as a consequence of incremental sentence production. Trends Linguist. Stud. Monogr. 152, 141-164. doi: 10.1515/9783110919585.141

Kempen, G., and Hoenkamp, E. (1987). An incremental procedural grammar for sentence formulation. Cogn. Sci. 11, 201-258. doi: 10.1207/s15516709cog $1102 \_5$

Konopka, A. E. (2012). Planning ahead: how recent experience with structures and words changes the scope of linguistic planning. J. Mem. Lang. 66, 143-162. doi: 10.1016/j.jml.2011.08.003

Konopka, A. E. (2013). "Discourse changes the timecourse of sentence formulation," in Poster Presented at the 19th Architectures and Mechanisms for Language Processing Conference, Marseille.

Konopka, A. E. (2014). "Speaking in context: discourse influences formulation of simple sentences," in Poster Presented at the 27th CUNY Human Sentence Processing Conference, Columbus, $\mathrm{OH}$.

Konopka, A. E., and Brown-Schmidt, S. (2014). "Message encoding," in The Oxford Handbook of Language Production, eds M. Goldrick, V. Ferreira, and M. Miozzo (Oxford: Oxford University Press), 3-20.

Konopka, A. E., and Kuchinsky, S. E. (2015). How message similarity shapes the timecourse of sentence formulation. J. Mem. Lang. 84, 1-23. doi: 10.1016/j.jml. 2015.04.003

Konopka, A. E., and Meyer, A. S. (2014). Priming sentence planning. Cognit. Psychol. 73, 1-40. doi: 10.1016/j.cogpsych.2014.04.001

Krifka, M. (2007). "Basic notions of information structure," in Interdisciplinary Studies of Information Structure 6, eds C. Fery and M. Krifka (Potsdam: Universitätsverlag).

Kruijff, G.-J. (2001). A Categorical-Modal Architecture of Informativity: Dependency Grammar Logic and Information Structure. Ph.D. thesis, Charles University, Prague.

Kuchinsky, S. E. (2009). From Seeing to Saying: Perceiving, Planning, Producing. Ph.D. dissertation, University of Illinois at Urbana-Champaign, Champaign, IL.

Kuchinsky, S. E., and Bock, K. (2010). "From seeing to saying: perceiving, planning, producing," in Paper Presented at the 23rd Meeting of the CUNY Human Sentence Processing Conference, New York, NY.

Ladd, R. (2008). Intonational Phonology, 2nd Edn. Cambridge: Cambridge University Press. doi: 10.1017/CBO9780511808814

MacWhinney, B., and Bates, E. (1978). Sentential devices for conveying givenness and newness: a cross-cultural developmental study. J. Verbal Learning Verbal Behav. 17, 539-558. doi: 10.1016/S0022-5371(78) 90326-2

McDonald, J. L., Bock, K., and Kelly, M. H. (1993). Word and world order: semantic, phonological, and metrical determinants of serial position. Cognit. Psychol. 25, 188-230. doi: 10.1006/cogp.1993.1005

Meyer, A. S. (1996). Lexical access in phrase and sentence production: results from picture-word interference tasks. J. Mem. Lang. 35, 477-496. doi: 10.1006/jmla. 1996.0026

Meyer, A. S., and Lethaus, F. (2004). "The use of eye tracking in studies of sentence generation," in The Interface of Language, Vision, and Action: Eye Movements and the Visual World, eds J. M. Henderson and F. Ferreira (New York, NY: Psychology Press), 191-212.

Meyer, A. S., Sleiderink, A. M., and Levelt, W. J. M. (1998). Viewing and naming objects: eye movements during noun phrase production. Cognition 66, B25-B33. doi: 10.1016/S0010-0277(98)00009-2

Norcliffe, E., Konopka, A. E., Brown, P., and Levinson, S. (2015). Word order affects the timecourse of sentence formulation in Tzeltal. Lang. Cogn. Neurosci. 30, 1187-1208. doi: 10.1080/23273798.2015. 1006238

Pierrehumbert, J., and Hirschberg, J. (1990). "The meaning of intonational contours in the interpretation of discourse," in Intentions in Communication, eds P. R. Cohen, J. Morgan, and M. E. Pollack (Cambridge, MA: MIT Press), 271-311.

Rochemont, M. (2016). Givenness, Oxford Handbook of Information Structure. Oxford: Oxford University Press. 
Schriefers, H., Teruel, E., and Meinshausen, R. M. (1998). Producing simple sentences: results from picture-word interference experiments. J. Mem. Lang. 39, 609-632. doi: 10.1006/jmla.1998.2578

Tanaka, M. N., Branigan, H. P., McLean, J. F., and Pickering, M. J. (2011). Conceptual influences on word order and voice in sentence production: evidence from Japanese. J. Mem. Lang. 65, 318-330. doi: 10.1016/j.jml.2011. 04.009

Wheeldon, L. R., and Lahiri, A. (1997). Prosodic units in speech production. J. Mem. Lang. 37, 356-381. doi: 10.1006/jmla.1997. 2517
Conflict of Interest Statement: The authors declare that the research was conducted in the absence of any commercial or financial relationships that could be construed as a potential conflict of interest.

Copyright (c) 2017 Ganushchak, Konopka and Chen. This is an open-access article distributed under the terms of the Creative Commons Attribution License (CC BY). The use, distribution or reproduction in other forums is permitted, provided the original author(s) or licensor are credited and that the original publication in this journal is cited, in accordance with accepted academic practice. No use, distribution or reproduction is permitted which does not comply with these terms. 